\title{
Social Behavior and Structure in Wild and Captive Groups of the African Wild Dog, Lycaon pictus (Temminck, 1820) (Carnivora: Canidae) ${ }^{1}$
}

\author{
Julie Chen ${ }^{2}$
}

\begin{abstract}
African wild dogs, Lycaon pictus, has a highly complex social system. This research examines whether this social structure is predominantly innate or learned by conducting a comparative analysis of the social structure and behavior of captive versus free-ranging African wild dogs. Field observations of captive African wild dogs were compared to the behaviors of wild populations gathered from studies to determine their degree of similarity in behaviors. In both captive vs free-ranging groups, the pack served as the unit of analysis. Research of captive groups was conducted through field observations at the Honolulu Zoo. High overlap would strongly suggest that African wild dog's social structures are largely innate, while the opposite would indicate that they are largely learned. The data collected indicates that captive groups express many of the behaviors displayed by wild groups, suggesting a genetic basis for those behaviors. This has important implications for conservation, as captive populations may adapt well to a wild environment and thus be viable candidates for rewilding programs to restore wild populations.
\end{abstract}

Key Words: African wild dogs, Lycaon pictus, ethology, innate behavior, learned behavior, Honolulu Zoo

\section{Introduction}

Like many cooperative breeding mammals, African wild dogs (AWD or wild dogs), Lycaon pictus (Temminck, 1820), have a highly organized and complex social structure (Figure 1). This paper examines whether the social structure and behavior of AWD is largely innate or learned by comparing wild versus captive wild dog groups in literature research as well as supplemented by personal observations of captive AWD. The paper's findings suggest that wild and captive groups exhibit highly similar behavior, therefore indicating that the social structure and behavior of AWD is predominantly innate. This has many implications for conservation strategies as it suggests captive bred AWD may be suitable candidates for wild release as they may have higher success rates for survival.

\footnotetext{
${ }^{1}$ Submitted on February 28, 2019. Accepted on March 15, 2019. Last changes received on May 28, 2019.

2 Department of Environmental Sciences and Policy, MSc Program, Johns Hopkins University, Washington, District of Columbia 20036 USA. Email: E-mail: hchen141@jhu.edu
}

DOI: 10.9784/LEB6(4)Chen.01

Electronically available on May 30, 2019. Mailed on May 31, 2019. 


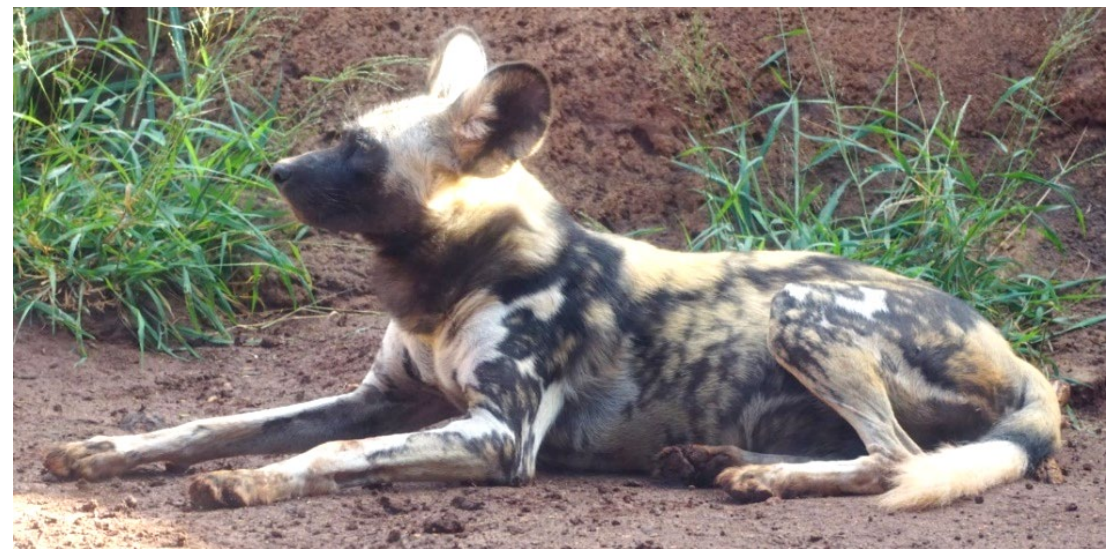

Figure 1. An African wild dog, Lycaon pictus (Temminck, 1820).

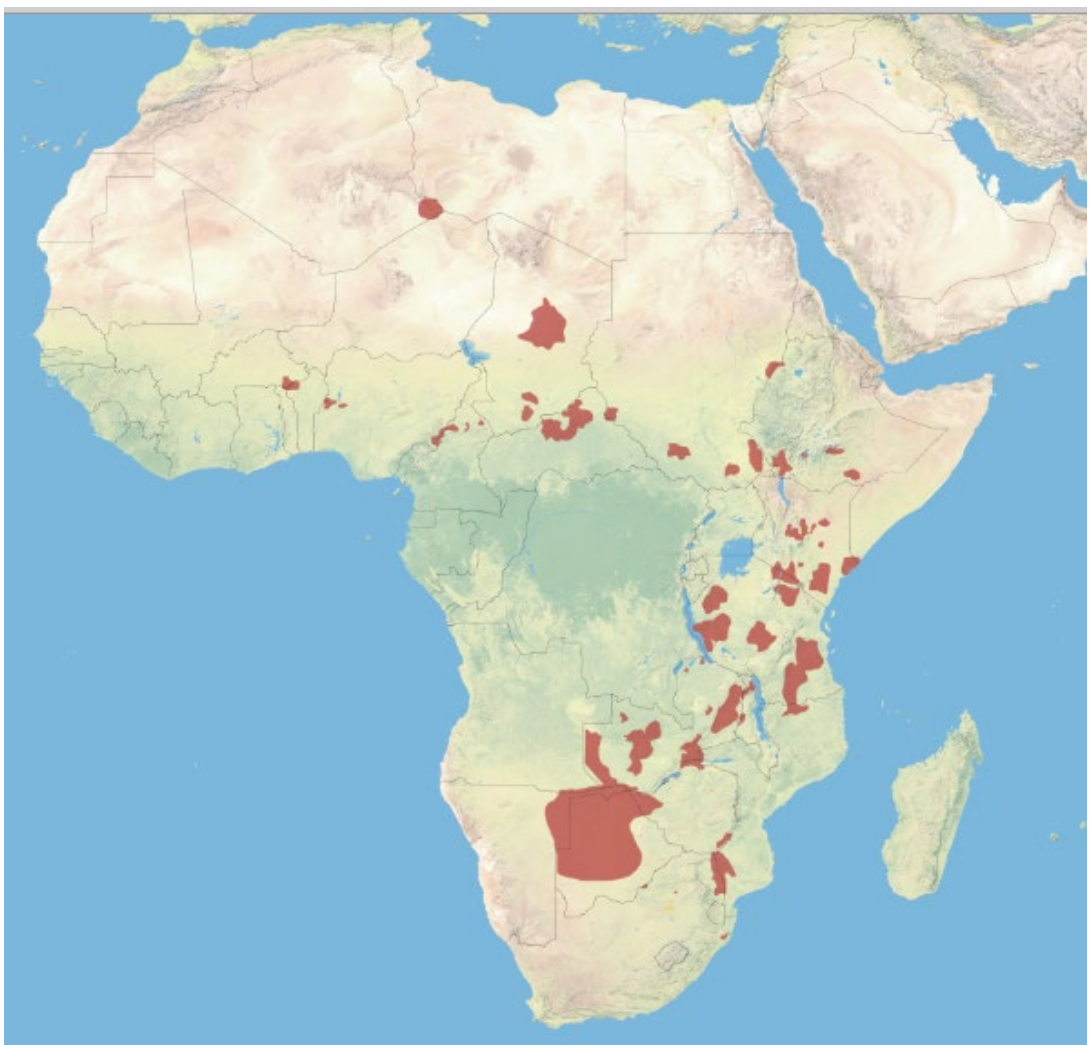

Figure 2. Geographical distribution of African wild dogs. IUCN Red List (Anonymous 2011, Woodroffe and Sillero-Zubiri 2012). 
African wild dogs are tall canids, weighing between $20-25 \mathrm{~kg}$ (Frame et al. 1979) with large round ears and characteristic patchwork of white, brown, yellow, and black markings on their coat (Tighe 2013). An endangered species, AWD are predominantly distributed in sub-Saharan Africa with populations as far south as South Africa (Creel et al. 1993, Jenkins et al. 2015 and Figure 2).

Wild dogs are highly cooperative, and the groups are usually composed of 2 to 30 animals although groups of 40 individuals have been reported (Creel et al. 1995, Mulheisen et al. 2002). Wild packs are made up of one breeding couple, known as the alpha pair, that monopolize reproduction in the group (Mulheisen et al. 2002, Anonymous 2018). Wild dogs are one of the few mammals that exhibit cooperative breeding, i.e. the entire pack helps in rearing the pups of the dominant pair, which is a unique evolutionary phenomenon that occurs in less than 3\% of mammals (Mills 1993, Bolton 2018). According to Derix (1994), for larger canids, such as wild dogs, the evolutionary development of communal breeding can be partly explained by female body size. With larger body weights, female wild dogs tend to produce larger litters of smaller neonates that require greater post-partum parental investment. This tends to increase competition among females for male support in rearing, pup defense and food provisioning, thus biasing towards a polyandrous social structure (Derix 1994). This is evidenced by wild dog packs dominated often by a single alpha female, greater emigration of other female members and a male-biased sex-ratio (Creel et al. 1993).

Other mammals, such as black-backed jackals, Canis mesomelas Schreber, 1775, and some species of birds, such as the greater anis, Crotophaga major (Gmelin, 1788) (Schieltz 2016), and the green woodhoopoe, Phoeniculus purpureus J. F. Miller, 1784 (Arnold et al. 1998), also display communal rearing, but this is not common in animals given the sacrifice of reproductive fitness by nonbreeding members (Malcolm and Marten 1982). However, nonbreeding members can enhance their reproductive fitness by improving the survival of relatives, which is the case with African wild dogs as pack members are predominantly related (Hamilton 1963, 1964a, 1964b, Frame et al. 1979, Smith 1964).

Wild packs are very closely bonded and display complex social behavior that reinforce relationships, confer rank, kinship, and communicate information (Mulheisen et al. 2002, De Villiers et al. 2003). According to Derix (1994), two explanations have been proposed for the evolution of wild dog's highly cooperative social structure, namely 'anti-predator defense' and 'better exploitation of food-resources'. Forming large cooperative groups is advantageous particularly where prey is large and scarce as group hunting increases the success rate of finding and bringing down prey. Furthermore, wild dogs have natural enemies such as hyenas and lions that compete in prey acquisition, therefore large packs enhance defense of members and captured prey (Derix 1994). 
This cohesive social system has accorded the pack a high degree of cooperation and coordination in hunting (Hubel 2016). Wild dogs employ cooperative hunting tactics over an expansive area that could range from 300 $\mathrm{km}^{2}$ to over $2000 \mathrm{~km}^{2}$ (Creel et al. 1993, Jenkins et al. 2015). Therein lies one of the challenges to wild dogs' conservation as an expansive range makes it challenging to monitor and protect the species. African wild dogs are listed as Endangered by IUCN with projections of greater decline (Woodroffe and Sillero-Zubiri 2012). Historically, AWD was severely extirpated by humans especially farmers but presently the main threats include habitat loss, land fragmentation, interspecific competition and infectious diseases (Gusset et al. 2006).

Effective conservation strategies would be integral to the future viability of this species. Wildlife conservation strategies have explored the use of translocation and reintroduction of captive and wild groups to help boost wild populations of endangered species (Jule et al. 2008). However, there are many challenges to these strategies with success rates ranging from $11 \%$ to $53 \%$ (Jule et al. 2008). A meta-study on the reintroduction of carnivores showed that only one in three captive-born animals survived in the wild, indicating a $70 \%$ mortality rate (Anonymous 2008). The low survival rate is directly related to the deficiencies in many key survival and social skills such as hunting, foraging, social interactions, breeding, nesting, and locomotory skills (Jule et al. 2008). Therefore, the findings from this study could inform conservation strategies as to whether captive wild dogs could be viable candidates for rewilding or replacement programs to restore free-ranging AWD populations. The assumption being that a high degree of behavioral overlap with wild populations of AWD would suggest captive populations possess a high degree of innate adaptability for survival in the wild.

\section{Methods}

To analyze whether the social behavior of wild dogs is predominantly innate or learned, this study is organized into four main sections: a review of the theories and studies of innate versus learned behavior in animals; the social structure and behavior of free-ranging AWD; the social structure and behavior of captive AWD; and a comparative analysis of the degree of overlap of the two groups. To address the first two sections a thorough literature review of relevant scientific papers and resources was conducted, including studies that examine the innate and learned behavior of animals and the social organization of wild AWD.

For the third section, field observations of captive African wild dogs were conducted at the Honolulu Zoo in Hawaii. As it was impossible to observe all potential behaviors of the captive group due to visitor limitations, this part of the study was supplemented by information reported by other scientific studies of captive AWD. The field studies were spread over six sessions from October to 
December 2018 and conducted in the early morning when the zoo opened or during mid-day (AWD are diurnal and hence most active during these hours) (Mulheisen et al. 2002). Observations were recorded with handwritten notes, photography, and video recordings. All photography in the study was supplied by the author. As the feeding area was out of sight both feeding and hunting behavior was impossible to observe. The enclosure is a long rectangular shaped space with two main viewing areas, one open air overlooking a ledge, the other covered with glass on the far end of the enclosure. The two viewing spots give access to areas the dogs commonly frequent.

Interviews conducted with staff members confirmed that the pack is eight members strong with one alpha mother and her seven pups, three females and four males. The pups were born in October 2017 hence they were just over a year old at the time of this research, which would make them yearlings (12-18 months old wild dogs). The alpha male passed away earlier in the year, hence was absent during the study. All members including the alpha mother were born in captivity, therefore any free-ranging wild dog behavior they exhibit would be innate. Furthermore, the zookeepers minimize human contact with the dogs in order to keep them as "wild" as possible. Interviews with zoo staff members and review of publications on the local pack was also conducted to gather relevant background information.

To conduct a comparative analysis, the study measured the percent overlap of wild vs. captive AWD social structure and behavior. These behavior elements are divided into three major categories that characterize African wild dogs: hierarchy and dominance (i.e. actions that express social rank); cooperation and cohesion (i.e. actions expressed during pack cooperation such as hunting or pup rearing); social bonding (i.e. actions that strengthen pack relations).

\section{Results}

\section{Innate vs. Learned Behavior in Animals}

Whether animal behavior is learned or innate has been at the heart of ethology. Undoubtedly, there is no clear separation between the two as learned behavior is often built upon the scaffolding of genetics (Breed 2010). It is widely accepted today that behavior is controlled by both genes and the environment (Breed 2010). However, it is also clear that the mechanisms for behavior lie on a wide spectrum, where at one extreme end are species that are highly controlled by innate behavior while at the opposite extreme are species that exhibit a high degree of learning (Cormier 2018). This has important implications for the survival of captive bred species in rewilding programs. Presumably, highly innate species such as amphibians would have greater survival rates when released from captivity than species with long instructional periods such as primates and cetaceans (Cormier 2018). 
Innate behavior is commonly characterized by low to no parental investment such as with fishes, amphibians, and reptiles (Cormier 2018). This is behavior that an animal is born with and will exhibit even if raised in isolation (Sipe 2018). In fact, it is part of an animal's genetic makeup and therefore less subject to modification (Sipe 2018). One of the best examples of innate behavior are sea turtles born with all the instincts required to dig out of their sand nest, head towards sea, survive, thrive and reproduce without ever acquiring that knowledge or guidance from their parents (Sipe 2018). Essentially, all the information for basic survival is hard-wired into their DNA and inherited (Sipe 2018). Similarly, wild Caledonian crows often construct complex sophisticated tools to probe for insects (Galef et al. 2005). Interestingly, hand reared Caledonian crows that have never observed tool making spontaneously develop the skill of tool making, although their tools are not as complex as their wild conspecifics (Galef et al. 2005). However, this shows that genetics play an important role in predisposing animals to certain behaviors, even though those behaviors may be perfected through experiences and practice (Thornton et al. 2011).

On the other hand, learned behavior is knowledge or skills acquired in life through trial and error as well as social learning (Sipe 2018, Thornton et al. 2011). Most often, offspring learn from observing or guidance from parents or other conspecifics (Sipe 2018). Learned behavior is flexible and modifiable and therefore not inherited (Gumbert 2000). Some well-known studies on learned animal behavior include classical conditioning, pioneered by Ivan Pavlov, where learned behavior occurred through association. Pavlov's dogs learned to associate food with the sound of bells (McLeod 2018). Operant conditioning, pioneered by B. F. Skinner, showed animals learned behaviors through repeated practice reinforced by a reward system (Staddon et al. 2002). For example, Hoppitt et al. (2012) showed that meerkats interaction with an experimental box containing a reward increased with the number of successful prior interactions.

Many studies focus on animal behavior through social learning. For example, the famous Koshima population of macaques in Japan displayed behavior of washing potatoes before eating (Galef 1992). Apparently, this action was first exhibited by a dominant female that slowly propagated throughout her troop so that nine years later potato washing was common (Galef 1992). Studies also show that bottlenose dolphin mothers can pass on complex foraging skills and tool use to their calves (Thornton et al. 2011). In fact, social learning has been attributed to the transfer of foraging, hunting and tool use skills in primates, cetaceans, and carnivores (Thornton et al. 2011). Hence, learning in animals often occurs through observations of more experienced conspecifics, confirming the importance of social learning.

However, more often there are no clear divide and behavior is a combination of both innate and learned mechanisms. In fact, genetics may predispose animals to certain behavior that is later honed through experience 
and social learning such as the example of the Caledonian crow mentioned above (Galef 1992). The line between innate and learned behavior is often blurred. For example, a study showed that naïve bumble bees have an innate preference for certain flower colors, presumably inherited through their DNA (Gumbert 2000). However, the bumble bees can learn to associate different colors to flower nectar and override their innate preferences. Interestingly, these innate preferences persist and are used as a "default" when the preferred flowers acquired through experiences are not available (Gumbert 2000). Similarly, an experiment showing naïve laboratory born monkeys TV images of their wild conspecifics being afraid of snakes also taught the laboratory-reared monkeys to fear snakes (Galef 1992). However, edited video images that appeared to show wild monkeys fearing flowers, did not have any effect on the laboratory-reared monkeys and they never learned to fear flowers (Galef 1992). A study by Feher et al. also showed that captive zebra finches raised in isolation will produce songs different from their wild conspecifics (2009). However, after four to five generations of iterative learning the progenies of those captive raised finches would produce songs very similar to their "wild-type," thus demonstrating the complex interplay between both genetics and learning (Fehrer 2009). These studies reveal that animal behavior is both innate and learned, however, learned behavior is often strongly predisposed to certain behavior governed by genetics (Thornton et al. 2011). This has important implications for this study as high overlap of social behavior between captive vs wild groups may indicate both groups are predisposed to the same genetic programming. As such, if released into the wild, captive groups may have the genetic programming that allows for similar adaptability as their wild born conspecifics.

\section{Social behavior and structure of wild African wild dogs}

Hierarchy and Dominance. African wild dogs exhibit many behaviors related to status and dominance. Their social organization is hierarchical with the alpha pair dominating the pack and monopolizing breeding (Frame et al. 1979). There are separate hierarchies for males and females, and dominance and submissive behaviors are expressed through different posturing and behaviors (Mulheisen et al. 2002, Creel et al. 1993). Behaviors related to dominance include breeding rights, level of aggression, coalition formation, urination, and sometimes even feeding priority. Often, only the alpha pair has breeding rights and the dominant female produces one litter of 8-20 pups per year (Creel et al. 1993, Frame et al. 1979, Anonymous 2018). In instances when a subordinate female also produces pups, the alpha female would usually attack the other mother, takeover her pups or kill them (Malcolm et al. 1982, Creel et al. 1993). Alpha females have been observed to show aggression by growling, biting, and charging subordinates to the ground (Anonymous 2018). To decrease the chance of subordinates mating, studies show that subordinate females have lower estrogen levels, males have less testosterone, and both are less aggressive 
than the alpha pair (Creel et al. 1993, Walker et al. 2017). During the mating period the alpha male displays elevated aggression and is observed defending the alpha female in estrous from other male wild dogs (Creel et al. 1993). Aggressive posturing is often characterized by low body position, ears laid back, mouth open, and teeth bared (Tighe 2013). On the other hand, submissive posturing is usually characterized by the subordinate rolling onto its back in front of the dominant member and or laying its ears flat against its head and rotating its head away (Malcolm et al. 1982).

In general, dominant wild dogs exhibit higher aggressive behaviors, particularly during mating periods and have leadership authority and control over the pack (Creel et al. 1993). They often chase away and attack predators, such as hyenas or lions from pup dens, which are the wild dog's natural enemies (Malcolm et al. 1982). The alpha wild dogs also decide the movement of the pack, especially during hunting when the alpha male often lead hunts and even decides whether to continue or end hunts (Hoa 2017, Frame et al. 1979). In general, the alpha female retains her status throughout her life, while alpha males are more likely to be deposed through challenges by subordinates (Frame et al. 1979). However, in general, outside of breeding periods and status challenges, AWD packs are relatively free of aggression between pack members, highlighting the strong kinship and social bonds in the group (Mulheisen et al. 2002). In fact, the evolutionary factors that drive for cooperative communal living in wild dogs, i.e. maximizing food-exploitation and defense against predators, predict for a more egalitarian society as the benefits of unconditional cooperation outweigh those of dominance aggression that could increase pack conflict (Derix 1994).

Studies also show that wild dogs form non-random coalitions that reflect the strength of relationships between members (Tighe 2013). Coalitions often form on lines of age, gender and rank (De Villiers et al. 2003). This makes sense as coalitions are power factions that either reinforce or challenge the existing hierarchy. For example, the alpha male often forms coalitions with beta males that prevent lower ranking dogs from launching a successful challenge (De Villiers et al. 2003). Interestingly, alpha males are more likely to spread their allegiance equally among pack members, possibly to prevent strengthening any one group from challenging his authority (De Villiers et al. 2003). Conversely, coalitions are strongest between members of the same sex and age, which explains the strong bonds between littermates (De Villiers et al. 2003). Later, this relationship assists younger wild dogs to maneuver in the social hierarchy such as challenging and deposing the older alpha male (De Villiers et al. 2003).

African wild dogs are not territorial, but urination and scent marking are an important part of their dominance posturing (Mulheisen et al. 2002). The alpha pair scent marks regularly and often at the same location with significant leg action such as raised hind legs, or even handstand, where both legs are raised in a hop (Frame et al. 1979, Jordan et al. 2013). Alpha females also often roll in 
the urine marked by the dominant male (Frame et al. 1979). Dominant wild dogs are also more likely to overmark, i.e., marking on top of an existing mark (Jordan et al. 2013). Interestingly, studies show that scent marks by dominant AWD are more likely to be investigated by other wild dogs (Jordan et al. 2013).

Feeding priority also reflects the existing hierarchy where the alpha female, pups and yearlings have priority to kills (Malcolm et al. 1982, Walker et al. 2017). After they eat their full, the adult males would start to feed usually in the order of the alpha male, beta males, and last the older gamma males (Malcolm et al. 1982). However, wild dogs often share food which involves the behavior of food acquisition where one dog will attempt to take food away from another dog (Tighe 2013). This is sometimes a type of dominance posturing and may occur as a group or individually (Tighe 2013).

Cooperation and Cohesion. The cornerstone of wild dog society is their strong cohesiveness and cooperative relationships. This cohesion governs the social structure of the pack and gives rise to unique and characteristic behavior. For example, AWD society has uniquely evolved cooperative breeding whereby the entire group helps raise the pups of the alpha pair (Bolton 2018). Wild dogs are also normally nomadic, but when there is a new litter the alpha female will den and keep the pack in one location until the pups grow up (Hoa 2017, Tighe 2013). During this time, the alpha female will usually remain behind on hunts to care for the pups as she is the only lactating female (Anonymous 2018, Malcolm et al. 1982). It has also been observed that other members, such as older subordinate males or younger females, at times "babysit" new pups (Hoa 2017, Malcolm et al. 1982). As babysitters often miss out on hunts, they also forgo opportunities to feed, demonstrating self-sacrifice for the betterment of the entire group (Malcolm et al. 1982). When the pack returns from a hunt, all members help feed the pups and alpha female by regurgitating meat to them (Mills 1993, Malcolm et al. 1982, Kuhme 1965). Pups often engage in begging behavior where they encourage regurgitation by licking the face of an adult accompanied by whining and begging sounds (Anonymous 2018). The cohesion in the pack is so strong that members will at times also regurgitate meat to care for the sick, injured and those that have not fed such as babysitters (Anonymous 2018, Mulheisen et al. 2002). The pack also protects the pups from predators which include hyenas, lions, leopards, cheetahs, and jackals (Malcolm et al. 1982). The wild dog's defensive posture includes high alertness, ears perked forward and rushing forward as a united pack, or stalking low, head close to the ground, hackles raised (Hoa 2017). Pack members have been observed to chase away intruders coming within $200 \mathrm{~m}$ of the den (Malcolm et al. 1982).

Hunting is also another activity that demonstrates the high level of cohesion and cooperation among AWD. Social rallying is a common behavior exhibited after resting or before a hunt (Tighe 2013). It is a highly ritualized act characterized by high energy involving multiple wild dogs even the whole pack 
jumping and nuzzling each other excitedly (Creel et al. 1995, Walker et al. 2017). Mobbing is a form of rallying when that excited energy is directed at a specific individual (Tighe 2013). This activity presumably helps prepare the pack for hunting by making sure the group is awake, alert, excited and coordinated (Creel et al. 1995). Usually, the rally is initiated when a member displays the initiation posture that involves rising from rest, with head lowered, mouth open and ears folded back (Walker et al. 2017). Successful rallies are often necessary precursors for collective movement and initiating a hunt (Walker et al. 2017). Interestingly, a study shows that the pack may have a type of voting system where "sneezing" may indicate support or lack thereof for a hunt (Walker et al. 2017). In fact, rally success positively correlated with the number of "sneezes," but when a dominant dog initiates a rally, it takes less "sneezes" to rouse the whole group, confirming the importance of rank (Walker et al. 2017).

Once a hunt is successfully initiated, packs always move together and oftentimes exhibit sophisticated cooperative and coordinated strategies (Hubel 2016, Creel et al. 1995). AWD are diurnal and hunt early in the morning, or early evening when prior hunts were unsuccessful (Anonymous 2018, Hoa 2017). The pack often travels in single file behind the lead who is frequently the dominant alpha male (Hoa 2017, Malcolm et al. 1982). They are known to chase their prey over long distances, known as coursing, and execute elaborate strategies such as relay running, spatial distribution, coordinated focus on single prey while taking on different roles and positioning (Hubel 2016). Studies have observed sophisticated tactics such as wild dogs fanning out and surrounding the target prey to entrap it (Hoa 2017). Members also play different roles in a hunt, such as leading, or chasing and driving a prey to others that are waiting for it (Hoa 2017). The pack also cooperate to bring down a prey such as pulling it to a halt or even distracting the prey in the front while others attack from the back (Creel et al. 1995). Clearly, hunting activities confirm the highly cohesive and cooperative nature of the African wild dog where members can communicate through body language and vocalizations (Hoa 2017).

Social bonds and Relationships. AWD members are very closely bonded to each other. For example, it has been shown that death in a pack member resulted in distressed behaviors such as whining, whimpering, and agitation (Anonymous 2018). The pack's close-knit relationships yield characteristic displays of behaviors which serve to strengthen bonds and pack cohesiveness. These include play, greetings, and resting associations. Play between pack members is displayed through different actions such as chasing where one wild dog will pursue another (Tighe 2013). The AWD being chased would often look back and have its rear under its body and move in a stiff exaggerated run (Tighe 2013). Parallel running is also a common play action, where members run flank to flank with each other (Walker et al. 2017). Rougher play such as pouncing on each other and play biting is also common during play (Tighe 
2013). Stalking can also be observed in play as well as dominance display. In play, the dog's body is low with ears folded back, and tail relaxed, but a dog about to exert its dominance will have its tail straight out and flared (Tighe 2013). There is also the play bow where a wild dog will stretch out its front legs and lower its chest to the ground all the while its rear remains raised (Tighe 2013). This action is believed to set the context for play (Tighe 2013).

Greeting is an important and large part of wild dog social behavior (Tighe 2013). It is believed to build social bonds, help identify members, and even reinforce hierarchy without aggressive displays (Tighe 2013). Greeting usually involve a combination of kneeling, nose touching, face licking, nuzzling face or front legs with chittering sounds (Mills 1993). More excited greeting display can involve gamboling and punching out forelegs at each other (Hoa 2017). Greeting commonly occur when members meet again after being separated or leaving a resting place (Hoa 2017, Mills 1993). Dominant greeting is also very characteristic with the dominant wild dog having a strong posturing that forcefully nuzzles the other dog, sometimes even pushing the subordinate to the ground into a submissive position or even lifting the dog with its head from under its body (Tighe 2013). Subordinates often initiate greetings with dominant dogs through gamboling actions, facial touching and excited chittering sounds (Anonymous 2018).

In the wild and in captivity wild dogs are often observed resting together. This behavior is far more significant than mere sleep, it constitutes a very integral part of the social structure of AWD. Wild dogs can be found resting after hunts and throughout the day (Anonymous 2018). Resting is characterized by multiple members lying together relaxed and bodies often touching (Mills 1993). In fact, wild dogs spend most of their time in close contact with each other (Mills 1993). Interestingly, resting associations are non-random but grouped in cohorts based on age and gender hence mirroring coalitions (De Villiers et al. 2003). For example, males of the same age group are more likely to rest together. This makes sense as resting associations are important in maintaining social bonds (Tighe 2013). Different types of resting associations have been observed such as heaping where two or more wild dogs lie in proximity and often touching. The interaction is passive, but the wild dogs are very much aware of each other such that if one dog moves the others would briefly engage with it through sniffing or other reactions (Tighe 2013). Chin resting is another resting behavior where one dog rests its chin on the back or body of another, the second may be standing or resting (Tighe 2013). Chin resting is believed to be a form of social communication (Tighe 2013).

Free-ranging African wild dogs have complex social structures and behaviors that give rise to a highly cohesive and cooperative functional unit. Table 1 lists the common behaviors exhibited in wild populations of AWD. Next, the paper will examine whether these same behaviors are observed in captive groups. 
Table 1. Social structure and behaviors of free-ranging African wild dogs. Figures refer to AWD observed at the Honolulu Zoo.

\begin{tabular}{|c|c|}
\hline Behavior & Description \\
\hline \multicolumn{2}{|r|}{ Hierarchy and Dominance } \\
\hline $\begin{array}{l}\text { Dominance } \\
\text { aggression } \\
\text { (Figure 3C) }\end{array}$ & $\begin{array}{l}\text { Mouth open, teeth bared, ears flat, body low to ground, } \\
\text { growling, charging subordinate to the ground. Often } \\
\text { displayed during fights over status, mating season, } \\
\text { disciplining subordinate, or food acquisition (Anonymous } \\
\text { 2018). }\end{array}$ \\
\hline $\begin{array}{l}\text { Scent marking } \\
\text { (Figure 4A) }\end{array}$ & $\begin{array}{l}\text { Urination that have significance such as signalling } \\
\text { dominance. Often accompanied by leg posturing (Jordan } \\
\text { et al. 2013). }\end{array}$ \\
\hline Overmarking & $\begin{array}{l}\text { Member urinating over or alongside an existing mark } \\
\text { (Jordan et al. 2013). }\end{array}$ \\
\hline Feeding hierarchy & $\begin{array}{l}\text { Alpha pairs and pups usually have priority in feeding. } \\
\text { However, wild dogs also share food freely with each } \\
\text { other regardless of rank, sex, or age (Tighe 2013). }\end{array}$ \\
\hline $\begin{array}{l}\text { Alpha dominance } \\
\text { (Figure 3A) }\end{array}$ & $\begin{array}{l}\text { Alpha dog leading hunts, charges against predators, and } \\
\text { deciding on movement and hunts (Walker et al. 2017). }\end{array}$ \\
\hline $\begin{array}{l}\text { Coalition } \\
\text { formation } \\
\text { (Figure 3B) }\end{array}$ & $\begin{array}{l}\text { Wild dogs form coalitions based on age, gender and rank. } \\
\text { Often to reinforce or challenge existing hierarchy (De } \\
\text { Villiers et al. 2003). }\end{array}$ \\
\hline
\end{tabular}




\section{Cooperation and Cohesion}

\begin{tabular}{|c|c|}
\hline Regurgitation & $\begin{array}{l}\text { As cooperative breeders, adult dogs often regurgitate food } \\
\text { to other members particularly pups. This usually occurs } \\
\text { after a hunt (Mulheisen et al. 2002). }\end{array}$ \\
\hline Babysitting & $\begin{array}{l}\text { When pack members stay behind to care for pups while } \\
\text { group goes hunting, usually older males or young females } \\
\text { (Hoa 2017). }\end{array}$ \\
\hline Food begging & $\begin{array}{l}\text { Pups lick adult face with whining and begging sounds to } \\
\text { encourage regurgitation of food. Behavior sometimes also } \\
\text { displayed by adults (Anonymous } 2018 \text {, Kuhme 1965). }\end{array}$ \\
\hline Defense mode & $\begin{array}{l}\text { High alert, ears forward, rushing forward or stalking low } \\
\text { to ground, hackles high, all dogs united. Usually occurs } \\
\text { when defending pups against predators (Hoa 2017). }\end{array}$ \\
\hline $\begin{array}{l}\text { Rally } \\
\text { (Figure 4B) }\end{array}$ & $\begin{array}{l}\text { High energy display of excitement and happiness that } \\
\text { involve many dogs jumping and nuzzling each other. } \\
\text { Usually occurs after long periods of separation, resting or } \\
\text { before a hunt (Tighe 2013). }\end{array}$ \\
\hline Mobbing & $\begin{array}{l}\text { A form of rallying when the high excitement energy is } \\
\text { directed at one individual (Tighe 2013). }\end{array}$ \\
\hline $\begin{array}{l}\text { Sneezing } \\
\text { (rallying) }\end{array}$ & $\begin{array}{l}\text { Wild dog sneezes during rallies have correlated with } \\
\text { initiating collective movement for hunts (Walker et al. } \\
\text { 2017). }\end{array}$ \\
\hline $\begin{array}{l}\text { Initiation posture } \\
\text { (rallying) }\end{array}$ & $\begin{array}{l}\text { Rising from rest with head lowered, mouth opened, and } \\
\text { ears folded back. Generally used to initiate a rally and } \\
\text { hunting (Walker et al. 2017). }\end{array}$ \\
\hline
\end{tabular}




\begin{tabular}{|c|c|}
\hline $\begin{array}{l}\text { Food acquisition } \\
\text { and sharing } \\
\text { (Figure } 4 \mathrm{C} \text { ) }\end{array}$ & $\begin{array}{l}\text { Wild dogs share food and oftentimes one dog takes food } \\
\text { from another dog. Sometimes this is dominance posturing } \\
\text { but rarely is there any aggression (Tighe 2013). }\end{array}$ \\
\hline \multicolumn{2}{|r|}{ Social Bonding } \\
\hline $\begin{array}{l}\text { Greeting } \\
\text { (Figures } 5 \mathrm{C} \\
\text { and } 7 \text { ) }\end{array}$ & $\begin{array}{l}\text { Combination of gambolling, facial licking, nuzzling face } \\
\text { and legs, nose touching, and excited chittering sounds. It } \\
\text { may also involve general sniffing or licking of the genital } \\
\text { areas. Greeting is a big part of wild dog social behavior } \\
\text { (Mills 1993). }\end{array}$ \\
\hline $\begin{array}{l}\text { Chasing (play) } \\
\text { (Figure 6A) }\end{array}$ & $\begin{array}{l}\text { One dog pursues another in play. The dog being pursued } \\
\text { would often look back, have its rear under its body and } \\
\text { run in an exaggerated stiff manner. Play reinforces pack } \\
\text { bonds (Tighe 2013). }\end{array}$ \\
\hline Bow (play) & $\begin{array}{l}\text { A dog would stretch out its front legs while lowering its } \\
\text { chest and keeping its rear end raised. Believed to set the } \\
\text { context for play (Tighe 2013). }\end{array}$ \\
\hline Pouncing (play) & $\begin{array}{l}\text { Dogs may pounce on each other when playing (Tighe } \\
\text { 2013). }\end{array}$ \\
\hline $\begin{array}{l}\text { Parallel running } \\
\text { (play) } \\
\text { (Figure 6B) }\end{array}$ & $\begin{array}{l}\text { Individuals run flank to flank with each other. Occurs } \\
\text { during play (Walker et al. 2017). }\end{array}$ \\
\hline $\begin{array}{l}\text { Biting (play) } \\
\text { (Figure 6D) }\end{array}$ & $\begin{array}{l}\text { Wild dogs often bite each other in play, the skin is not } \\
\text { broken (Tighe 2013). }\end{array}$ \\
\hline
\end{tabular}




\begin{tabular}{|l|l|}
\hline $\begin{array}{l}\text { Stalking } \\
\text { (Figure 6C) }\end{array}$ & $\begin{array}{l}\text { Stalking can occur as a precursor to play or exert a dog's } \\
\text { dominance. In play, dog's body is low, ears are folded } \\
\text { back but tail is relaxed. During dominance, dog's tail is } \\
\text { held straight out and flared (Tighe 2013). }\end{array}$ \\
\hline $\begin{array}{l}\text { Heap (resting } \\
\text { associations) } \\
\text { (Figure 5A) }\end{array}$ & $\begin{array}{l}\text { Heaping is when two or more dogs lie together in } \\
\text { proximity while resting. These resting associations are } \\
\text { non-random often based on rank, age and gender (De } \\
\text { Villiers et al. 2003). }\end{array}$ \\
\hline $\begin{array}{l}\text { Chin resting } \\
\text { (resting } \\
\text { association) } \\
\text { (Figure 5B) }\end{array}$ & $\begin{array}{l}\text { One dog would rest its chin on the body or back of } \\
\text { another. Constitutes a form of social communication } \\
\text { (Tighe 2013). }\end{array}$ \\
\hline
\end{tabular}

\section{Social behavior and structure of captive African wild dogs}

The results show that the captive group display many of the behaviors expressed by wild groups. These include behaviors related to dominance and hierarchy such as coalition formation, especially on gender lines. For example, three males were observed investigating a puddle of water after heavy rain while the rest of the group was resting or spread apart (Figure 3B). The males were also often engaged in play, or resting associations. Interestingly, the alpha female nearly always rested alone and further apart, which makes sense given she has no equal rank in the group. Other studies also confirm coalition formation in captive groups on the lines of age, gender and rank (De Villiers et al. 2003, Bultron 1977). The alpha female also appears to lead and control the pack's movement, as is often the case in the wild particularly during hunts where the pack frequently move single file behind the alpha lead (Hoa 2017). On one occasion the alpha female moved to the back of the enclosure presumably where the food is kept, and the entire pack roused themselves and followed her single file (Figure 3A).

Although rare, dominance aggression was also exhibited by the alpha female. On one occasion she lashed out at a yearling with growls and bared teeth (Figure 3C). At the time she was chewing on a bone when the yearling approached possibly to acquire the food item. Interestingly, the alpha female immediately dropped the bone and went into "greeting" mode where she ran to nearby yearlings and sniffed and licked their faces and multiple dogs quickly mobbed around her. In the end, the yearling that was rebuffed was able to acquire the food item. Scent-marking versus regular urination was challenging 
to determine in the group, however on occasion a member would urinate where other members would immediately sniff (Figure 4A). Furthermore, other studies have observed scent-marking in captive populations (Bultron 1977, Tighe 2013).

As the captive group did not need to hunt many of the behaviors related to cooperative breeding was more challenging to observe. However, it appeared on occasion the group displayed high energy excitement characterized by chittering sounds, gamboling, group mobbing and nuzzling often identified as rallying or play (Figure 4B). Other studies have also observed rally-like actions in captive groups (Bultron 1977, Tighe 2013). Food acquisition, a common behavior after hunts in the wild, was also observed where captive dogs would share or take a food item from another dog with little aggression (Figure 4C). Regurgitation of food items was not observed in this study, however Bultron's study of captive wild dogs clearly confirmed regurgitation by adults when solicitated by pups through food begging behavior characterized by chittering sounds and facial nibbling (1977).

Resting associations occupied a significant part of the captive group. In fact, the captive dogs were observed resting most of the time. Heaping was a common sight where multiple dogs would lie together in proximity (Figure 5A). Often the yearlings would be resting together in different combinations from all together, or in separate smaller groups, most likely reflecting coalitions. The alpha female often rested alone and separate. Chin resting was also observed where an individual rested its chin on another's body (Figure 5B). Greeting was the second most common behavior observed confirming its importance in the social relationships of African wild dogs. Greeting behavior often initiated when members reunite after separation or when a member joins a resting group (Figure 5C). A memorable occasion occurred when one member, possibly the alpha female rejoined the other members who were resting. The whole group burst into excited chittering, jumping, facial licking and sniffing that appeared like a rally, however, the alpha female went to each member and preformed the greeting action. General sniffing, including of the genitals, is also a part of greeting and that was also observed.

Characteristic play behavior was also displayed in the captive group, although not as often as resting associations or greeting. The actions included play chasing where on one occasion a wild dog appeared to goad other members to chase it, which they did. Other play behavior included parallel running, play stalking and even play biting (Figure 6). Figures 3-6 display the behaviors observed in captive groups of African wild dogs. 

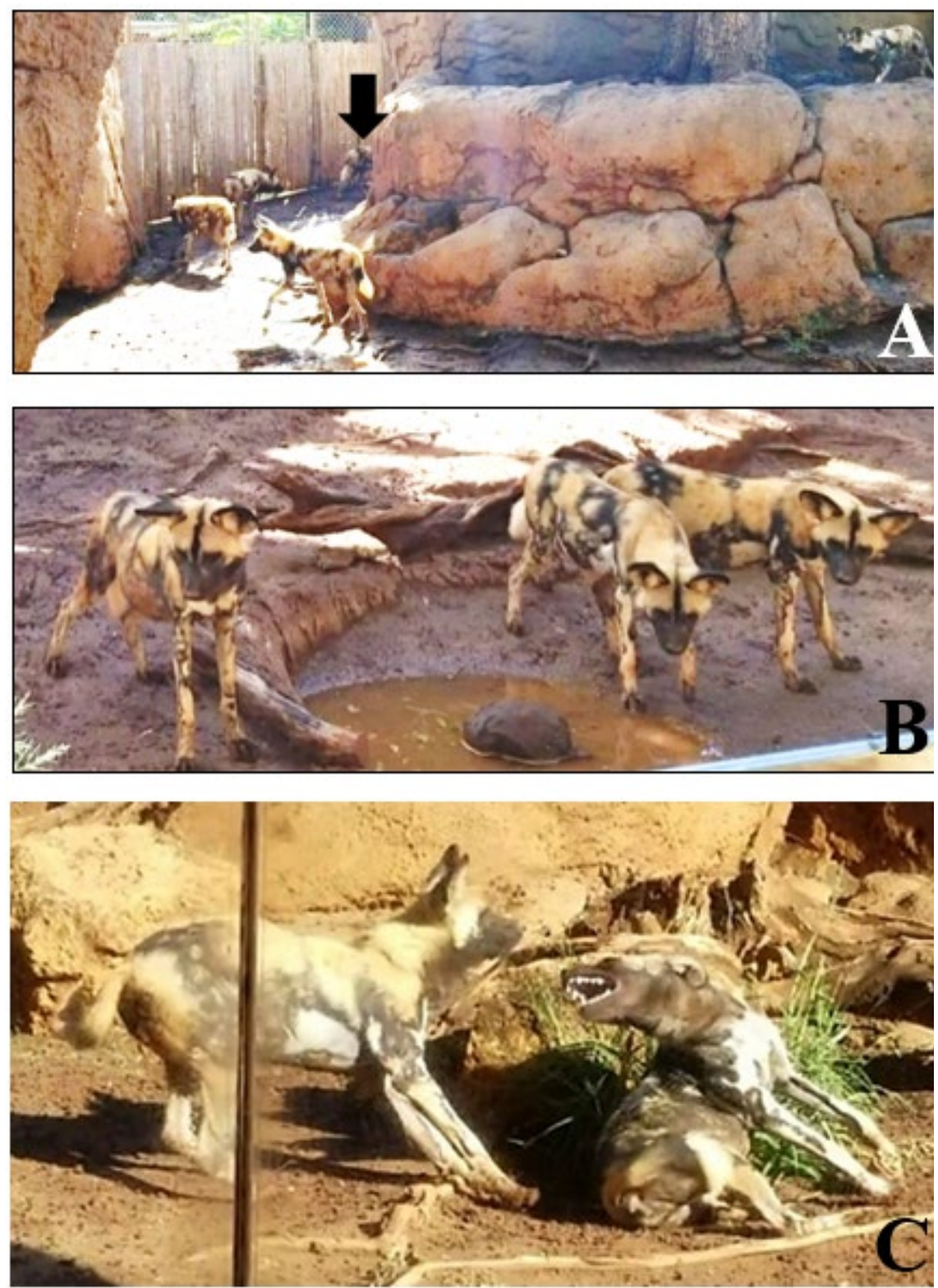

Figure 3. Behaviors of African wild dogs in captivity. A. Alpha dominance (pack follows alpha female, noted by arrow, to feeding area), B. Coalition formation (three males are observed investigating a puddle), C. Dominance aggression (alpha female targets yearling). 

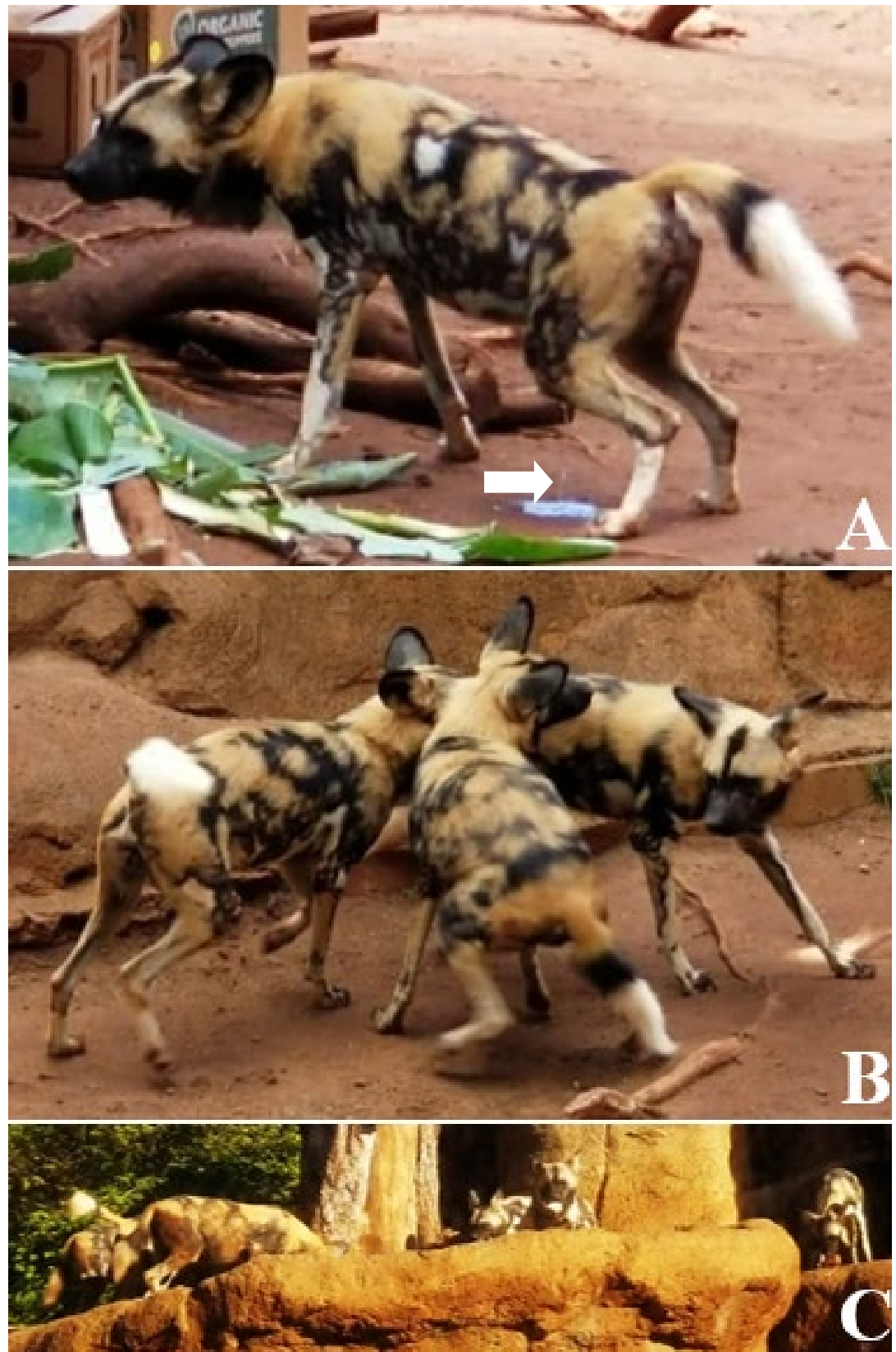

Figure 4. Behaviors of African wild dogs in captivity. A. Scent marking, B. Rallying, C. Food acquisition and sharing. Arrow on A points to urine stream. 

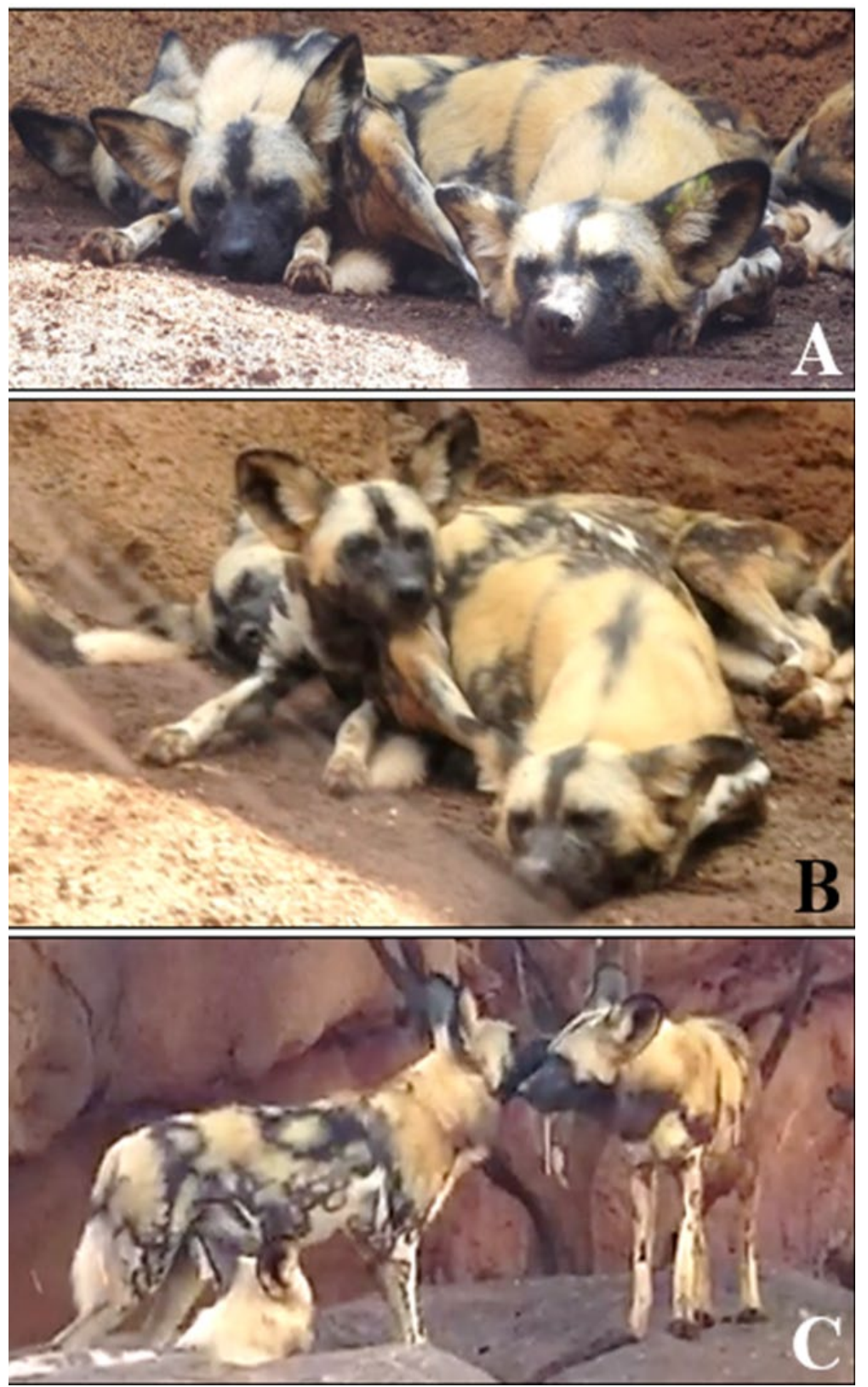

Figure 5. Behaviors of African wild dogs in captivity: A. Heaping (resting association), B. Chin Rest, C. Greeting. 

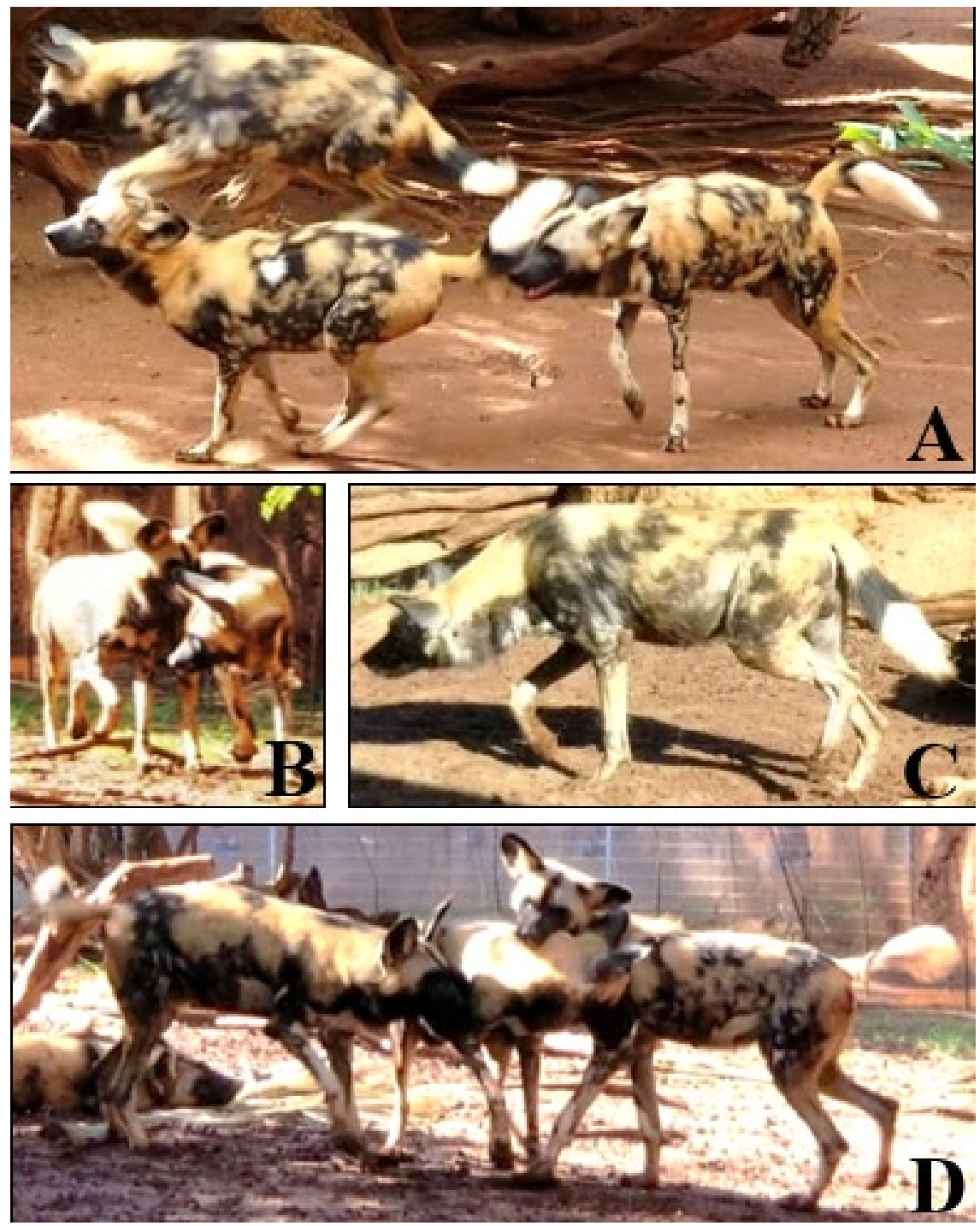

Figure 6. Behaviors of African wild dogs in captivity: A. Chasing (play), B. Parallel Running (play), C. Stalking (play), D. Biting (play). 


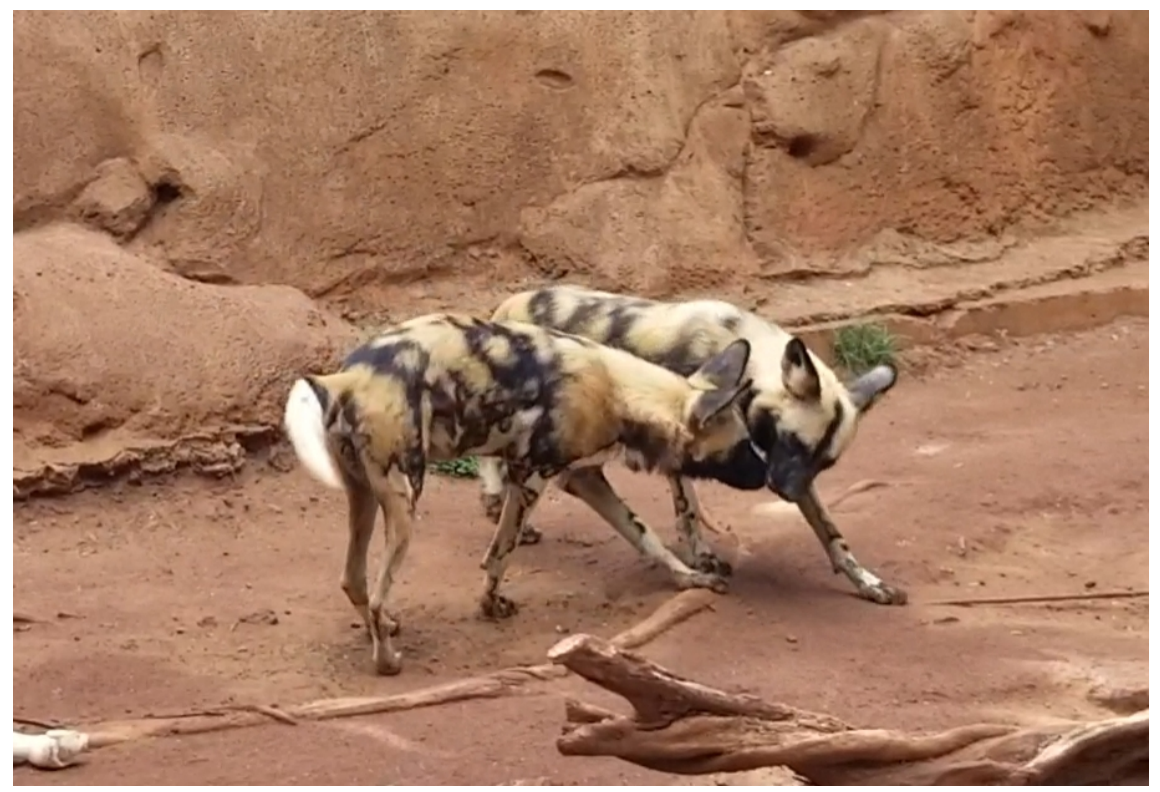

Figure 7. Two African wild dogs greeting. This is an example of social bonding.

\section{Discussion}

There is a high degree of overlap between wild versus captive wild dog groups. Tables 1 and 2 lists all the behavior elements analyzed in this study and Table 3 compares the overlap between free-ranging and captive groups. The area of greatest overlap is in social bonding behaviors where there is $100 \%$ overlap, meaning all the social bonding behaviors reported in wild groups were also observed in the captive group. This is not surprising as captivity did not inhibit the group from expressing behaviors of social bonding. Members of the captive group were all related as siblings and parent which reflect the natural pack relationships found in the wild. The fact that identical mannerisms and ways of expression would spontaneously develop in captive groups indicates the preponderance of innate mechanisms in governing wild dog social structures.

The second most correlated behavior category is hierarchy and dominance with $83 \%$ overlap. There was only one behavior of this category that was not observed in captivity, feeding hierarchy, which is difficult to observe as the feeding area was out of visitor sight. However, other studies of captive AWD groups make no mention of it, therefore further research is needed. Interestingly, the occurrence of coalition formation and alpha dominance is significant. Coalition formation grew increasingly pronounced over the twomonth duration of the field observations. In the beginning, the yearlings were almost always together, but as the months passed the group appeared to separate 
on gender lines with the males more likely to move and interact together. As reflected in wild populations, yearlings start to jockey for position and power as they mature (De Villers et al. 2003). These behaviors have also been reported in other studies of captive groups (De Villers et al. 2003, Bultron 1977). Therefore, their display in captivity indicate the strong innate nature of the wild dog's social structures.

The third and least correlated category of behaviors is cooperation and cohesion. Out of the nine behaviors reported in wild populations, five $(56 \%$ overlap) were observed in captive groups. As noted, regurgitation was not directly observed in this study, but another study on captive wild dogs observed clear indications of this behavior (Bultron 1977). The smaller percentage of overlap in this category is not surprising as these behaviors are related to hunting and the communal rearing of litter which is greatly limited in captivity. Furthermore, the "sneezing" behavior that is believed to express support or lack thereof for a hunt, has only been reported in one study hence requires further investigation into its relevance (Walker et al. 2017). Rallies (high energy displays involving many dogs jumping and nuzzling each other and often occurs after long periods of separation, resting or before a hunt) were observed in the study group however they were often hard to distinguish from play, but other studies have confirmed their occurrence in captive groups (Tighe 2013, Bultron 1977).

Table 2. Comparison of behavior elements of African wild dogs in the wild vs. in captivity, with comments.

\begin{tabular}{|c|c|c|}
\hline Wild & Captive & Comments \\
\hline \multicolumn{3}{|c|}{ Hierarchy and Dominance } \\
\hline Dominance aggression & Yes & \\
\hline Scent marking & Yes & \\
\hline Overmarking & Yes & \\
\hline Feeding Hierarchy & No & $\begin{array}{l}\text { Feeding area in zoo out of visitor's } \\
\text { sight. }\end{array}$ \\
\hline Alpha dominance & Yes & \\
\hline Coalition formation & Yes & \\
\hline
\end{tabular}




\begin{tabular}{|c|c|c|}
\hline \multicolumn{3}{|c|}{ Cooperation and Cohesion } \\
\hline Regurgitation & Yes & $\begin{array}{l}\text { Not observed in this study but } \\
\text { confirmed in other study (Bultron } \\
\text { 1977). }\end{array}$ \\
\hline Babysitting of pups & No & $\begin{array}{l}\text { Not applicable as captive groups do } \\
\text { not hunt or have communal pup } \\
\text { rearing. }\end{array}$ \\
\hline Food begging & Yes & $\begin{array}{l}\text { Other studies have reported this } \\
\text { behavior in captivity. }\end{array}$ \\
\hline Defense mode & No & $\begin{array}{l}\text { Not applicable as captive groups do } \\
\text { not hunt. }\end{array}$ \\
\hline Rally & Yes & $\begin{array}{l}\text { Rallies are like play and it is difficult } \\
\text { to distinguish between them. There } \\
\text { is chasing in Play, Rally is more an } \\
\text { aim to get group excited before a } \\
\text { hunt. }\end{array}$ \\
\hline Mobbing & Yes & \\
\hline Sneezing (rallying) & No & $\begin{array}{l}\text { Wild dogs are too far away to hear } \\
\text { behavior; behavior not reported in } \\
\text { other studies. }\end{array}$ \\
\hline Initiation posture (rallying) & No & $\begin{array}{l}\text { Nor applicable as captive group does } \\
\text { not hunt. }\end{array}$ \\
\hline Food acquisition and sharing & Yes & \\
\hline \multicolumn{3}{|c|}{ Social Bonding } \\
\hline Greeting & Yes & \\
\hline Chasing (play) & Yes & \\
\hline Bow (play) & Yes & \\
\hline Pouncing (play) & Yes & \\
\hline
\end{tabular}




\begin{tabular}{|l|c|l|}
\hline Parallel running (play) & Yes & \\
\hline Biting (play) & Yes & \\
\hline Stalking (play) & Yes & \\
\hline Heap (resting associations) & Yes & \\
\hline Chin resting (resting associations) & Yes & \\
\hline
\end{tabular}

Table 3. Percent overlap of African wild dog behaviors in the wild vs. in captivity.

\begin{tabular}{|l|c|c|c|}
\hline Behavior Category & Wild & Captive & Percent Overlap $^{\mathbf{3}}$ \\
\hline Hierarchy and dominance & 6 & 5 & 83 \\
\hline Cooperation and cohesion & 9 & 5 & 56 \\
\hline Social bonding & 9 & 9 & 100 \\
\hline Total & $\mathbf{2 4}$ & $\mathbf{1 9}$ & $\mathbf{7 9}$ \\
\hline
\end{tabular}

The total percent overlap in behaviors is relatively high, 79\% (Table 3). Other comparative studies also reported high behavioral overlap (Tighe 2013, Bultron 1977). In fact, one study reported near $100 \%$ overlap except for sexual behaviors, which was prevented in captivity (Tighe 2013). These findings indicate that the social structures and behaviors of African wild dogs are highly innate. In theory, this suggests that wild dogs are like other species that rely heavily on their genetic inheritance for survival, such as sea turtles (Sipe 2018). Therefore, the behaviors of captive AWD populations are very similar to their wild counterparts. This has important implications for conservation strategies as captive populations may be viable candidates for rewilding programs to restore wild populations.

Undoubtedly, certain survival skills, such as those related to hunting, cannot be as developed in captivity as in the wild. Evidence also shows varied hunting strategies in wild populations which confirm that hunting is partly a learned skill (Hoa 2017, Anonymous 2018). Furthermore, studies also confirm that

\footnotetext{
${ }^{3}$ Percentage overlap for each category determined by dividing behavior in column "Captive" by "Wild" and multiplying by 100.
} 
reintroduced captive born AWD have low survival rates with deaths mainly caused by humans, starvation, interspecies competition, and diseases (Jule et al. 2008). In other words, captive-born wild dogs lack the skills to avoid humans as well as dangerous competitors, to hunt, and are more susceptible to diseases in the wild (Jule et al. 2008, Owens 2008). In fact, this study group was so habituated to their captivity that they showed neither fear of human visitors nor to the roar of lions in the nearby pen. Normally, wild AWD learn to fear both groups. However, the strong innate behavior of wild dogs shows the potential to successfully rewild captive born AWD through well-designed strategies that address these shortcomings such as recreating wild conditions in captivity.

Furthermore, as demonstrated by captive-born monkeys that learn to fear snakes but not flowers (Galef 1992) or Caledonian crows that spontaneously develop tool use (Galef 1992), genetics can predispose animals to develop certain behaviors under the right pressures. Along the same line of reasoning, captive AWD placed in the wild may also naturally develop adaptations that increase its survival particularly if first habituated to "wild" conditions before release. Further field studies are necessary to determine how well captive populations survive in the wild.

The objective of this study was to compare the social structures and behaviors of wild vs captive African wild dogs to determine if behaviors are likely to be predominantly innate or learned. The results from this study show $79 \%$ overall overlap, which is supported by other studies that also report high correlations (De Villers et al. 2003, Bultron 1977). However, there are some shortcomings in this study that should be addressed in future research. First, the list of behaviors analyzed was not exhaustive but instead represented some core behaviors. Behaviors that are limited by captivity, such as courtship and population dispersal, was not examined. Second, field observations of captive animals were not comprehensive given the limitation to visitor access and hours. For example, feeding areas were out of sight and so observations of feeding behavior were limited. Third, captivity prevents expression of many natural behaviors such as hunting, communal pup rearing, and dispersal. In addition, said study group only consisted of two generations (mother and yearlings) where in wild populations, the genetic relationships are far more complex.

However, the high behavioral overlap observed, suggests that captive AWD may be genetically predisposed to express similar behaviors as their wild conspecifics when exposed to the same environmental pressures. This study shines promising light on the conservation of African wild dogs. Captive breeding may be a viable solution to restoring wild populations of African wild dogs especially when coupled to the right rewilding program.

Acknowledgments

Five reviewers revised this paper and offered valuable suggestions. 


\section{Literature Cited}

Anonymous. 2008. Captive carnivores not up to wild living. Science Daily. University of Exeter. Retrieved December 26, 2018 from www.sciencedaily.com/releases/2008/01/080121080406.htm

Anonymous. 2011. The Distribution of African Wild Dogs. Wikipedia. Retrieved from https://en.wikipedia.org/wiki/African_wild_dog\#/media/File:African_Wild_Dog_Distrbution.j pg

Anonymous. 2018. Wild Things. Wild Dogs Biting Back Wild Things. YouTube Video 49:50. Posted [February 17, 2018] https://www.youtube.com/watch? $=$ CSrqCUdRKjg\&t $=809 \mathrm{~s}$

Arnold, K. E. and I. P. E Owens. 1998. Cooperative breeding in birds: a comparative test of the life history hypothesis. Proceedings of the Royal Society B Biological Sciences 265:739-745. https://doi.org/10.1098/rspb.1998.0355

Bolton, R. 2018. Researching the social behaviour of African Painted Dogs. Act for Wildlife. May 20, 2018. Retrieved from https://www.chesterzoo.org/news/researching-the-social-behaviourof-african-painted-dogs/

Breed, M. and L. Sanchez. 2010. Both environment and genetic makeup influence behavior. Nature Education Knowledge 3(10):68.

Bultron, D. 1977. Social Structure of a Captive Group of African Wild Dogs (Lycaon pictus). A Thesis Submitted to the Faculty of the Graduate School of the University of Minnesota. Minneapolis, Minnesota, USA. 82 pp.

Creel, S. and N. Marusha Creel. 1995. Communal hunting and pack size in African wild dogs, Lycaon pictus. Animal Behavior 50:1325-1339. https://doi.org/10.1016/0003-3472(95)80048-4

Creel, S., N. M. Creel, M. G. L. Mills, and S. L. Monfort. 1993 Rank and reproduction in cooperatively breeding African wild dogs: behavioral and endocrine correlates. Behavioral Ecology 8(3):298-306. https://doi.org/10.1093/beheco/8.3.298

Cormier, Z. 2018. Can Captive Animals Ever Truly Return to the Wild. BBC. Retrieved from https://www.bbcearth.com/blog/?article=can-captive-animals-ever-truly-return-to-the-wild

Derix, R. R. W. M. 1994. The Social Organization of Wolves and African Wild Dogs: An Empirical and Model-Theoretical Approach. Thesis Universiteit Utrecht. Faculteit Biologie, Universiteit Utrecht. Utrecht, The Netherlands. $151 \mathrm{pp}$.

De Villiers, M. S., P. R. K. Richardson, and A. S. van Jaarsveld. 2003 Patterns of coalition formation and spatial association in a social carnivore, the African wild dog (Lycaon pictus). Journal of Zoology 260(4):377-389. https://doi.org/10.1017/S0952836903003832

Fehér, O., H. Wang, S. Saar, P. P Mitra, and O. Tchernichovski. 2009. De novo establishment of wild-type song culture in the Zebra Finch. Nature 459:1-8. https://doi.org/10.1038/nature07994

Frame, L. H., J. R. Malcolm, G. W. Frame, and H. Van Lawick. 1979. Social Organization of African Wild Dogs (Lycaon pictus) on the Serengeti plains, Tanzania 1967-1978. Zeitschrift für Tierpsychologie 50(3):225 https://doi.org/10.1111/j.1439-0310.1979.tb01030.x

Galef B. G. Jr. 1992. The question of animal culture. Human Nature 3:157-178. https://doi.org/10.1007/BF02692251

Galef, B. G. Jr. and K. N. Laland. 2005 Social learning in animals: empirical studies and theoretical models. American Institute of Biological Sciences 55(6):489-499. https://doi.org/10.1641/00063568(2005)055[0489:SLIAES]2.0.CO;2

Gumbert, A. 2000. Color choices by bumble bees (Bombus terrestris): innate preferences and generalization after learning. Behavioral Ecology and Sociobiology 48(1):36-43. https://doi.org/10.1007/s002650000213

Gusset, M., R. Slotow, and M. J. Somers. 2006. Divided we fail: the importance of social integration for there-introduction of endangered African wild dogs (Lycaon pictus). Journal of Zoology (London) 270:502-511. https://doi.org/10.1111/j.1469-7998.2006.00168.x

Hamilton, W. D. 1963. The evolution of altruistic behaviour. American Naturalist 97:354-356. https://doi.org/10.1086/497114

Hamilton W. D. 1964a. The genetical evolution of social behaviour. I. Journal of Theoretical Biology 7(1):1-16. https://doi.org/10.1016/0022-5193(64)90038-4 
Hamilton W. D. 1964b. The genetical evolution of social behaviour. II. Journal of Theoretical Biology 7(1):17-52. https://doi.org/10.1016/0022-5193(64)90039-6

Hoa, S. 2017 NAT GEO WILD-The Park of Wild Dogs. YouTube Video, 45:30. Posted [April 1, 2017] Best Documentary 2017 NAT GEO WILD - The Pack Wild Dogs

Hoppitt, W., J. Samson, K. N. Laland, and A. Thornton. 2012. Identification of learning mechanisms in a wild meerkat population. Plos One 7(8): 1-11. https://doi.org/10.1371/journal.pone.0042044

Hubel, T. Y. 2016. Additive opportunistic capture explains group hunting benefits in African wild dogs. Nature Communications 7:1-11 https://doi.org/10.1038/ncomms11033

Jenkins, E., M. Silva-Opps, S. B. Opps, and M. R. Perrin. 2015. Home range and habitat selection of a reintroduced African wild dog (Lycaon pictus) pack in a small South African game reserve. African Journal of Wildlife Research 45(2):233-246. http://dx.doi.org/10.3957/056.045.0233

Jordan, N. R., K. A. Golabek, P. J. Appst, G. D. Gilfillan, and J. W. McNutt. 2013. Scent-mark identification and scent-marking behaviour in African wild dogs (Lycaon pictus). Ethology 119:644-652. https://doi.org/10.1111/eth.12105

Jule, K. R., L. Leaver, and S. Lea. 2008. The effects of captive experience on reintroduction survival in carnivores: A review and analysis. Biological Conservation 141:355-363. https://doi.org/10.1016/j.biocon.2007.11.007

Kuhme, W. 1965. Communal food distribution and division of labour in African hunting dogs. Nature 205:443-444. https://doi.org/10.1038/205443a0

Malcolm, J. R. and K. Marten. 1982. Natural selection and the communal rearing of pups in African wild dogs (Lycaon pictus). Behavioral Ecology and Sociobiology 10(1):1-13. https://doi.org/10.1007/BF00296390

McLeod, S. 2018. Pavlov's Dogs. Simply Psychology. Retrieved from https://www.simplypsychology.org/pavlov.html

Mills, M. G. L. 1993. Social systems and behaviour of the African wild dog Lycaon pictus and the spotted hyaena Crocuta crocuta with special reference to rabies. Journal of Veterinary Research 60:405-409.

Mulheisen, M. and C. Allen. 2002. Lycaon pictus (online). Animal Diversity Web. Accessed November 22, 2018. https://animaldiversity.org/accounts/Lycaon pictus/

Schieltz, J. 2016. Researcher studies communal nesting in birds. Science $X$. https://phys.org/news/2016-01-birds.html

Sipe, M. 2018. What is innate and learned animal behavior. Sciencing. April 24, 2018. Retrieved from https://sciencing.com/innate-learned-animal-behavior-6668264.html

Smith, J. M. 1964. Group selection and kin selection". Nature 201(4924):1145-1147. https://doi.org/10.1038/2011145a0

Staddon, J. E. and D. T. Cerutti. 2002. Operant Conditioning. Annual Review of Psychology 54:115144. https://doi.org/10.1146/annurev.psych.54.101601.145124

Tighe, E. E. 2013. The effects of captivity on display-based communication and social interaction in the captive African Wild dog (Lycaon pictus). Thesis. Master of Science in Biological Science. University of Canterbury. New Zealand. 102 pp. Retrieved from https://core.ac.uk/download/pdf/35470592.pdf

Thornton A. and T. Clutton-Brock. 2011. Social learning and the development of individual and group behaviour in mammal societies. Philosophical Transactions of the Royal Society BBiological Sciences 366:978-987. https://doi.org/10.1098/rstb.2010.0312

Walker, R. H., A. J. King, W. McNutt, and N. R. Jordan. 2017. Sneeze to leave: African wild dogs (Lycaon pictus) use variable quorum thresholds facilitated by sneezes in collective decisions. Proceedings of the Royal Society B Biological Sciences 284(1862). https://doi.org/10.1098/rspb.2017.0347

Wilde, J. 2015. What happens when captive animals are released? Seeker. Retrieved from https://www.seeker.com/what-happens-when-captive-animals-are-released-1792645644.html

Woodroffe, R. and C. Sillero-Zubiri. 2012. Lycaon pictus. The IUCN Red List of Threatened Species. $\quad$ Retrieved 31 March 2019: e.T12436A16711116. https://doi.org/10.2305/IUCN.UK.2012.RLTS.T12436A16711116.en 